\title{
Ground-Penetrating Radar Evaluation of Moisture and Frost across Typical Saskatchewan Road Soils
}

\author{
Curtis Berthelot, ${ }^{1}$ Diana Podborochynski, ${ }^{1}$ Timo Saarenketo, ${ }^{2}$ \\ Brent Marjerison, ${ }^{3}$ and Colin Prang ${ }^{4}$ \\ ${ }^{1}$ Department of Civil and Geological Engineering, University of Saskatchewan, 57 Campus Drive, Saskatoon, SK, Canada S7N 5 A9 \\ ${ }^{2}$ Roadscanners Oy, Urheilukate 5-7, 96100 Rovaniemi, Finland \\ ${ }^{3}$ Preservation and Surfacing, Saskatchewan Ministry of Highways and Infrastructure, 350 3rd Avenue North, \\ Saskatoon, SK, Canada S7K $2 \mathrm{H} 6$ \\ ${ }^{4}$ Infrastructure Preservation, City of Saskatoon, 222 3rd Avenue North, Saskatoon, SK, Canada S7K 0J5
}

Correspondence should be addressed to Curtis Berthelot, curtis.berthelot@usask.ca

Received 6 November 2009; Revised 22 April 2010; Accepted 20 July 2010

Academic Editor: Abolfazl Mohammadian

Copyright (C) 2010 Curtis Berthelot et al. This is an open access article distributed under the Creative Commons Attribution License, which permits unrestricted use, distribution, and reproduction in any medium, provided the original work is properly cited.

\begin{abstract}
This study was undertaken to evaluate the effect of soil type, moisture content, and the presence of frost on road substructure permittivity. Permittivity sensitivity of typical road soils was characterized in the laboratory to provide baseline dielectric constant values which were compared to field ground penetrating radar (GPR) survey results. Both laboratory devices, the complex dielectric network analyzer and the Adek Percometer, as well as the field GPR system were used in this study to measure the dielectric constant of soils. All three systems differentiated between coarse-grained and fine grained soils. In addition, at temperatures below freezing, all three systems identified an increase in water content in soils; however, when frozen, the sensitivity of dielectric constant across soil type and moisture content was significantly reduced. Based on the findings of this study, GPR technology has the ability to characterize in situ substructure soil type and moisture content of typical Saskatchewan road substructure soils. Given the influence of road soil type and moisture content on in-service road performance, this ability could provide road engineers with accurate estimates of in situ structural condition of road structures for preservation and rehabilitation planning and optimization purposes.
\end{abstract}

\section{Introduction}

This study was undertaken to evaluate the effect of soil type, moisture content, and the presence of frost on road substructure permittivity. Permittivity sensitivity of typical road soils was characterized in the laboratory to provide baseline dielectric constant values which were compared to field ground penetrating radar (GPR) survey results. Both laboratory devices, the complex dielectric network analyzer and the Adek Percometer, as well as the field GPR system were used in this study to measure the dielectric constant of soils. All three systems differentiated between coarse-grained and fine grained soils. In addition, at temperatures below freezing, all three systems identified an increase in water content in soils; however, when frozen, the sensitivity of dielectric constant across soil type and moisture content was significantly reduced. Based on the findings of this study, GPR technology has the ability to characterize in situ substructure soil type and moisture content of typical Saskatchewan road substructure soils. Given the influence of road soil type and moisture content on in-service road performance, this ability could provide road engineers with accurate estimates of in situ structural condition of road structures for preservation and rehabilitation planning and optimization purposes.

Approximately two thirds of the Saskatchewan highway network consists of thin asphalt surfacing placed on a thin granular base layer or placed directly on a prepared subgrade. Because of their age, most Saskatchewan in-service thin asphalt pavements have been subjected to significant climatic 


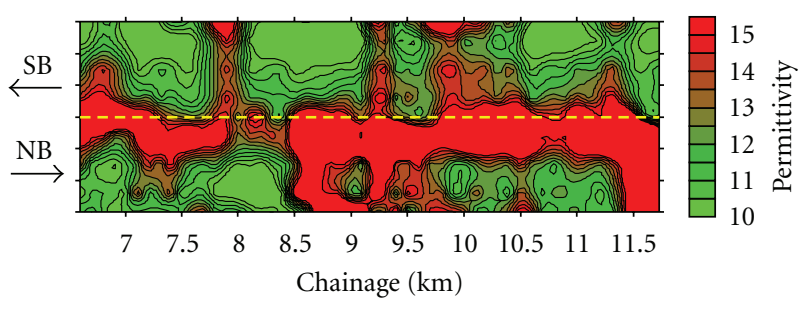

FIGURE 1: Subgrade permittivity contour.

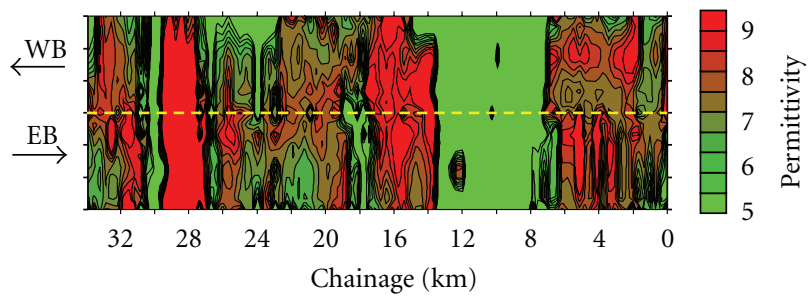

FIGURE 2: Granular base permittivity contour.

effects and many freeze-thaw cycles [1-3]. In recent years, Saskatchewan thin paved highways have seen increases in traffic volumes, increases in truck weights, and insufficient preventative maintenance budgets. Saskatchewan flexible pavements also tend to be thinner than standard AASHTOtype pavement structures, and as such the substructure granular base and subgrade soil layers are expected to contribute significantly to the load-carrying capacity and structural performance of Saskatchewan thin hot mix asphalt concrete (HMAC) pavements. Therefore, the structural capacity of Saskatchewan thin pavements is directly influenced by in situ moisture content and frost action, including freeze-thaw cycles [1-4].

Conventional approaches to determine the moisture content of road structure sublayers include core sampling and time-domain reflectometry (TDR), both of which are destructive, invasive, and time consuming [5-7]. In addition, these conventional methods only provide point measurements of the road structure moisture state. Due to the typical variability of moisture content commonly exhibited by Saskatchewan road structures spatially, point measurements may not provide an accurate or complete representation of road structure moisture content [5-7]. Therefore, Saskatchewan road agencies are piloting the use of ground penetrating radar to determine in situ road structure characteristics.

Ground-penetrating radar (GPR) is a nondestructive road structure diagnostic technology. GPR reflections transmitted through a road structure can determine sub-layer electromagnetic properties [5-9]. The electromagnetic property most commonly measured by road engineers is the dielectric constant (e) because it is primarily influenced by soil water content [6-9]. From a material engineering perspective, soils are composite material systems comprised of inorganic minerals, organic particles, water, and air. As a result, the dielectric characteristics of soil are a function of the dielectric constants of the individual soil components,

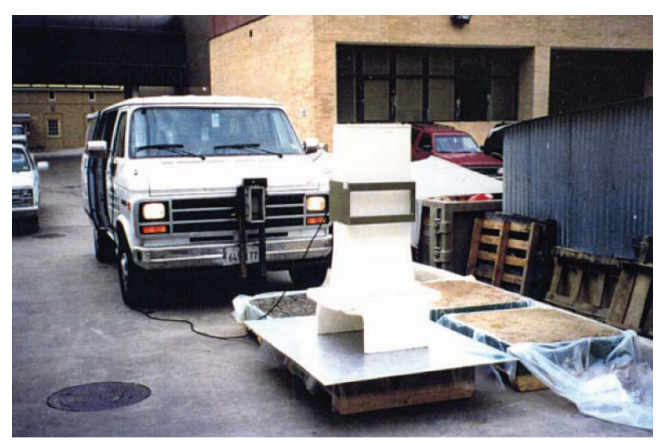

FIgURE 3: Ground penetrating radar and box test sample.

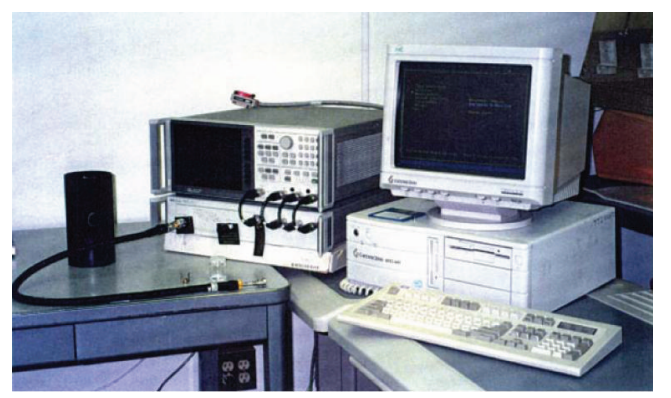

Figure 4: Hewlett packard complex dielectric network analyzer.

TABLE 1: Dielectric values of typical road soil and layer constituents.

\begin{tabular}{lc}
\hline Constituent & Dielectic value \\
\hline Air & 1 \\
Freshwater & 8 \\
Ice & 4 \\
Bedrock (granite) & $5-7$ \\
Clay & $25-40$ \\
Silt & $16-30$ \\
Silty sand & $7-10$ \\
Sand subbase & $4-6$ \\
Gravel base & $4-7$ \\
Glacial till & $8-18$ \\
Asphalt concrete & $4-8$ \\
Slag asphalt concrete & $8-15$ \\
Portland cement concrete & $8-10$ \\
Bitumen bound base & $6-7$ \\
Cement bound base & $8-10$ \\
\hline
\end{tabular}

the volume fraction of each soil component, the geometrics of the soil components, and the electrochemical interactions between components [10]. Table 1 summarizes published dielectric constants of typical road soil constituents [11].

Given the dielectric constant values summarized in Table 1, it is hypothesized that the permittivity of typical Saskatchewan road soils can be accurately determined through laboratory characterization of known soil compositions representative of field state conditions. The objective of this study was to employ two laboratory test methods, the 


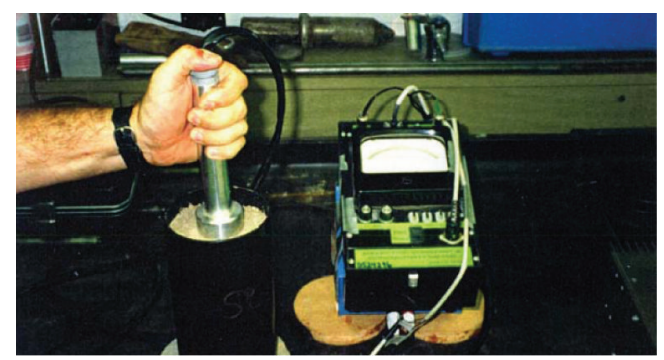

FIGURE 5: Adek percometer surface dielectric probe equipment.

complex dielectric network analyzer and the surface dielectric probe, to characterize the dielectric properties of typical soils commonly used for road construction in Saskatchewan. These laboratory measures were then compared to typical field GPR-measured dielectric constant values.

\section{GPR Background}

Traditional road engineering applications using GPR include determining structural layer thickness, locating in situ anomalies within the road substructure, characterizing stripping and segregation within the HMAC surfacing, locating geological aggregate sources, and detecting delamination of bridge decks $[4,8,9]$. In addition, GPR can be used to collect water content information over a large area on a continuous, noninvasive basis [5-9]. Previous research has also identified correlations between the relative permittivity of soils and moisture content, soil frost heave, and clay content of soils [12-14].

Based on several field surveys in Saskatchewan and elsewhere, GPR has demonstrated the ability for road engineers to identify relative moisture content and the presence of frost within thin road structures on a nearly continuous basis at highway speeds [4-9]. Engineers could benefit in two primary ways from determining the dielectric constants of road materials in the laboratory. Firstly, road engineers will be able to evaluate in-field GPR road profile survey data with increased accuracy in order to determine the in situ road layer composition as related to field performance. Secondly, road engineers will be able to examine soil mechanical behaviour across variable moisture and density field state conditions in the laboratory and spatially relate the field structural performance of roads to in situ soil composition and moisture content using GPR.

To illustrate the application of GPR in characterizing the in situ substructure moisture content of road structures, the in situ subgrade permittivity is illustrated as a contour plot for each road layer on a typical Saskatchewan thin paved highway, Control Section (C.S.) 49-09, as shown in Figure 1. Figure 1 shows significant variability in the subgrade permittivity profile. The subgrade relative permittivity ranged from less than 10 to greater than 15 , which is typical of a low-plastic clay-silt material [11]. The relatively low subgrade permittivity (green area) of C.S. 49-09 shows portions of the subgrade that are relatively dry, whereas the
TABLE 2: Standard proctor optimum dry density and moisture content data of soils considered in study.

\begin{tabular}{lcc}
\hline Soil type & $\begin{array}{c}\text { Standard proctor dry } \\
\text { optimum density } \\
\left(\mathrm{kg} / \mathrm{m}^{3}\right)\end{array}$ & $\begin{array}{c}\text { Optimum standard } \\
\text { proctor moisture } \\
\text { content } \\
(\%)\end{array}$ \\
\hline $\begin{array}{l}\text { Glacial-alluvium } \\
\text { gravel base }\end{array}$ & 2220 & 7 \\
$\begin{array}{l}\text { Clay-till subgrade } \\
\begin{array}{l}\text { High plastic } \\
\text { lacustrine clay } \\
\text { subgrade }\end{array}\end{array}$ & 1820 & 16 \\
\hline
\end{tabular}

high permittivity (red area) shows the subgrade areas that are relatively wetted up $[2,8]$.

To further illustrate the use of GPR to evaluate in situ road granular base material, Figure 2 illustrates the granular base permittivity of C.S. 49-04. As seen in Figure 2, the granular base layer permittivity of C.S. 49-04 varied from 5 to 10 across the length of the surveyed area. From km 7.500 to $\mathrm{km} 14.000$, the granular base permittivity profile was approximately five, which corresponds to the dielectric constant of a relatively dry granular base representative of a granular base at or slightly below optimum moisture content [11]. The permittivity profile illustrated in Figure 2 also shows several areas of C.S. 49-04 that are exhibiting a relatively high granular base permittivity, which is an indication of wetting up in the granular base layer. These permittivity values were confirmed based on subsequent targeted grade hole, and core samples were retrieved from the field and documented elsewhere [2].

\section{Experimental Approach}

The objective of this study was to use both the field GPR system as well as the two laboratory test devices (the complex dielectric network analyzer and the surface dielectric probe) to evaluate the sensitivity of the permittivity of Saskatchewan road soils across typical moisture contents experienced in the field. In addition, the soil samples were tested at plus 20 degrees celsius and minus 20 degrees celsius to evaluate the effect of frost on the permittivity measurements of typical Saskatchewan road soils. The second objective of this study was to compare the permittivity results obtained from the two laboratory test devices to the permittivity values obtained from the field GPR system results.

\section{Experimental Configuration}

Three soils used in the typical construction of Saskatchewan roads were used for this project: crushed glacial-alluvium gravel base, clay-till subgrade, and high plastic lacustrine clay subgrade. All samples were compacted to optimum dry density and tested at two temperatures: plus 20 degrees celsius and minus 20 degrees celsius. These two temperatures represent limits of thawed and frozen field state conditions for this study. Soils were also tested at three moisture 
contents: optimum standard Proctor moisture content and at a minimum and maximum water content determined based on in situ moisture contents typically experienced in the field $[2,4]$.

The optimum standard Proctor moisture content and dry optimum density for each material considered in this research is listed in Table 2. As seen in Table 2, the optimum standard Proctor moisture content and dry optimum density of the glacial-alluvium gravel base were $2220 \mathrm{~kg} / \mathrm{m}^{3}$ and seven percent, respectively. The optimum standard Proctor moisture content and dry optimum density of the claytill subgrade were $1820 \mathrm{~kg} / \mathrm{m}^{3}$ and 16 percent, respectively. The optimum standard Proctor moisture content and dry optimum density of the high plastic lacustrine clay subgrade were $1350 \mathrm{~kg} / \mathrm{m}^{3}$ and 30 percent, respectively.

\section{Experimental Procedures}

Each soil type was subjected to permittivity measurements using three technologies: one $\mathrm{GHz}$ central frequency aircoupled field GPR, a complex dielectric network analyzer laboratory meter, and a surface dielectric probe with electrical conductivity laboratory meter.

5.1. GPR Equipment. GPR is a nondestructive technology that employs variable frequency air- and/or ground-coupled antenna and provides permittivity measurements taken on a continuous basis over a large area. To provide measurements as would be in a typical GPR survey, one meter square box samples of $150 \mathrm{~mm}$ depth were prepared, as shown in Figure 3. The sample boxes were treated with sealant and lined with polyethylene and wax to prevent moisture from diffusing or evaporating out of the soil sample during conditioning and GPR testing. The bottom of the sample boxes were lined with tin so the bottom of each sample could be easily identified in the GPR signal. Sealed box samples were conditioned at temperatures of plus 20 degrees celsius and minus 20 degrees celsius using computer-feedbackcontrolled environmental chambers for ten days to ensure that samples reached the temperature equilibrium.

Scullion et al. [14] have documented equations to determine a soil's dielectric constant (within a two-layer system) based on the reflected GPR. These equations are summarized in

$$
\begin{gathered}
\varepsilon_{a}=\left[\frac{1+\left(A_{o} / A_{m}\right)}{1-\left(A_{o} / A_{m}\right)}\right]^{2}, \\
\sqrt{\varepsilon_{b}}=\sqrt{\varepsilon_{a}}\left[\frac{1-\left[A_{o} / A_{m}\right]^{2}+\left[A_{1} / A_{m}\right]}{1-\left[A_{o} / A_{m}\right]^{2}-\left[A_{o} / A_{m}\right]}\right],
\end{gathered}
$$

where $\varepsilon_{a}$ represents relative permittivity measurement of surface layer, $\varepsilon_{b}$ denotes relative permittivity measurements of base layer, $A_{1}$ is amplitude of base reflection, $A_{o}$ symbolizes amplitude of surface reflection and $A_{m}$ stands for amplitude of metal plate reflection.

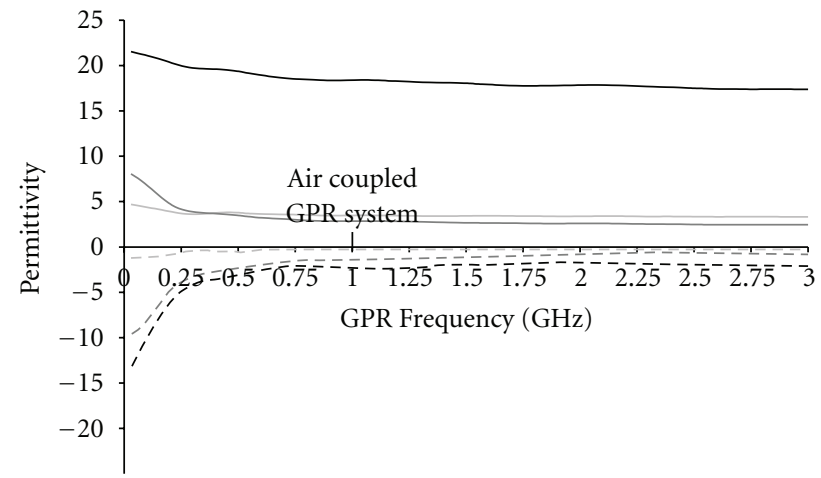

(a) $+20^{\circ} \mathrm{C}$
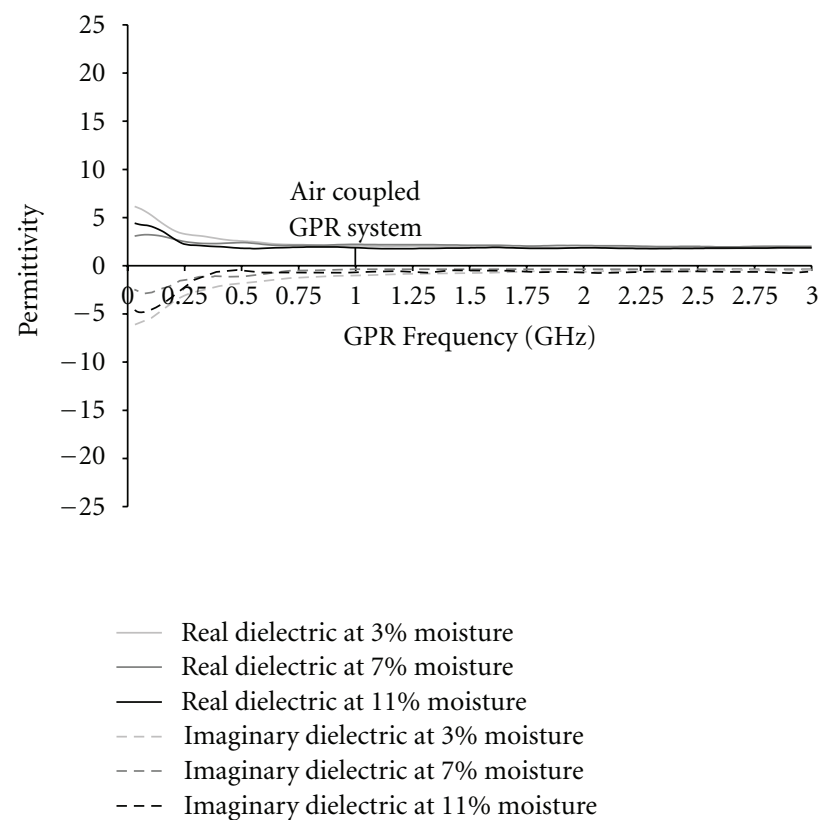

(b) $-20^{\circ} \mathrm{C}$

Figure 6: Complex dielectric network analyzer results of glacialalluvium gravel base.

5.2. Complex Dielectric Network Analyzer Laboratory Equipment. The complex dielectric network analyzer measures real and imaginary permittivity across frequencies ranging from $0.03 \mathrm{GHz}$ to $3.0 \mathrm{GHz}$. To assess the real and imaginary portions of the permittivity signal across soil type and moisture content, permittivity characterization tests were conducted on the three soils using a Hewlett Packard network analyzer, pictured in Figure 4.

The complex dielectric network analyzer used in this study employed a sealed-surface probe (while in contact with the surface material) to measure permittivity. The complex dielectric network analyzer back calculated the material's permittivity based on known dielectric constant measurements of three calibration materials: air, distilled water, and gold-plated copper. Samples of the three soils were prepared at standard Proctor optimum dry density in $100 \mathrm{~mm}$ by $200 \mathrm{~mm}$ polyvinylchloride cylindrical containers. The complex dielectric, $\varepsilon^{*}$, of a material may be written in 
Table 3: Summary of Permittivity Results at $+20^{\circ} \mathrm{C}$ and $-20^{\circ} \mathrm{C}$.

\begin{tabular}{|c|c|c|c|c|c|c|c|c|}
\hline \multirow[b]{2}{*}{ Soil Type } & & \multirow[b]{2}{*}{$\begin{array}{l}\text { Gravimetric } \\
\text { Moisture } \\
\text { Content }(\%)\end{array}$} & \multirow[b]{2}{*}{$\begin{array}{c}\text { Volumetric } \\
\text { Water Content } \\
(\%)\end{array}$} & \multirow[b]{2}{*}{$\begin{array}{l}\text { GPR System } \\
\quad(1 \mathrm{GHz})\end{array}$} & \multicolumn{3}{|c|}{ Permittivity Results } & \multirow[b]{2}{*}{$\begin{array}{c}\text { Adek } \\
\text { Percometer } \\
\text { Difference GPR } \\
\text { System }\end{array}$} \\
\hline & & & & & $\begin{array}{c}\text { Complex } \\
\text { Dielectric } \\
\text { Network } \\
\text { Analyzer } \\
(1 \mathrm{GHz})\end{array}$ & $\begin{array}{c}\text { Complex } \\
\text { Dielectric } \\
\text { Network } \\
\text { Analyzer } \\
\text { Difference from } \\
\text { GPR System }\end{array}$ & $\begin{array}{c}\text { Adek } \\
\text { Percometer } \\
(50 \mathrm{MHz})\end{array}$ & \\
\hline \multicolumn{9}{|c|}{ Temperature $=+20^{\circ} \mathrm{C}$} \\
\hline \multirow{3}{*}{$\begin{array}{l}\text { Glacial- } \\
\text { Alluvium } \\
\text { Gravel Base }\end{array}$} & Min. & 3 & 7 & 4.6 & 4.5 & $-0.1(-2.2 \%)$ & 3.0 & $-1.6(-34.8 \%)$ \\
\hline & Opt. & 7 & 16 & 6.9 & 4.4 & $-2.5(-36.2 \%)$ & 4.0 & $-2.9(-42.0 \%)$ \\
\hline & Max. & 11 & 24 & 10.8 & 18 & $7.2(66.7 \%)$ & 11.0 & $0.2(1.9 \%)$ \\
\hline \multirow{3}{*}{$\begin{array}{l}\text { Clay-Till } \\
\text { Subgrade }\end{array}$} & Min. & 12 & 22 & 8.5 & 4.4 & $-4.1(-48.2 \%)$ & 6.0 & $-2.5(-29.4 \%)$ \\
\hline & Opt. & 16 & 29 & 17.6 & 22.3 & $4.7(26.7 \%)$ & 20.0 & $2.4(13.6 \%)$ \\
\hline & Max. & 21 & 38 & 19.8 & 28.6 & $8.8(44.4 \%)$ & 21.0 & $1.2(6.1 \%)$ \\
\hline \multirow{3}{*}{$\begin{array}{l}\text { High Plastic } \\
\text { Lacustrine } \\
\text { Clay Subgrade }\end{array}$} & Min. & 25 & 34 & 8.6 & 7.6 & $-1.0(-11.6 \%)$ & 11.0 & $2.4(27.9 \%)$ \\
\hline & Opt. & 30 & 41 & 28.6 & 31.6 & $3.0(10.5 \%)$ & 31.0 & $2.4(8.4 \%)$ \\
\hline & Max. & 40 & 54 & 32.0 & 38.6 & $6.6(20.6 \%)$ & 36.0 & $4.0(12.5 \%)$ \\
\hline \multicolumn{9}{|c|}{ Temperature $=-20^{\circ} \mathrm{C}$} \\
\hline \multirow{3}{*}{$\begin{array}{l}\text { Glacial- } \\
\text { Alluvium } \\
\text { Gravel Base }\end{array}$} & Min. & 3 & 7 & 3.9 & 2.3 & $-1.6(-41.0 \%)$ & 3.0 & $-0.9(-23.1 \%)$ \\
\hline & Opt. & 7 & 16 & 4.4 & 2.2 & $-2.2(-50 \%)$ & 3.0 & $-1.4(-31.8 \%)$ \\
\hline & Max. & 11 & 24 & 4.0 & 2.1 & $-1.9(-47.5 \%)$ & 4.0 & $0.0(0.0 \%)$ \\
\hline \multirow{3}{*}{$\begin{array}{l}\text { Clay-Till } \\
\text { Subgrade }\end{array}$} & Min. & 12 & 22 & 5.8 & 4.1 & $-1.7(-29.3 \%)$ & 5.0 & $-0.8(-13.8 \%)$ \\
\hline & Opt. & 16 & 29 & 7.3 & 4.1 & $-3.2(-43.8 \%)$ & 6.0 & $-1.3(-17.8 \%)$ \\
\hline & Max. & 21 & 38 & 6.3 & 4.2 & $-2.1(-33.3 \%)$ & 6.0 & $-0.3(-4.8 \%)$ \\
\hline \multirow{3}{*}{$\begin{array}{l}\text { High Plastic } \\
\text { Lacustrine } \\
\text { Clay Subgrade }\end{array}$} & Min. & 25 & 34 & 7.2 & 4.6 & $-2.6(-36.1 \%)$ & 5.0 & $-2.2(-30.6 \%)$ \\
\hline & Opt. & 30 & 41 & 10.9 & 4.7 & $-6.2(-56.9 \%)$ & 8.0 & $-2.9(-26.6 \%)$ \\
\hline & Max. & 40 & 54 & 9.6 & 4.8 & $-4.8(-50.0 \%)$ & 9.0 & $-0.6(-6.3 \%)$ \\
\hline
\end{tabular}

terms of the real and imaginary components of the radar signal, as seen in

$$
\varepsilon^{*}=\varepsilon^{\prime}-i\left[\varepsilon^{\prime \prime}+\frac{\sigma_{d c}}{\omega \varepsilon_{0}}\right]
$$

where $\varepsilon^{\prime}$ is real part of the relative dielectric constant, $\varepsilon^{\prime \prime}$ denotes frequency dependent loss component of the relative dielectric constant, $\sigma_{d c}$ represents relative dielectric constant conductivity, $\omega$ stands for angular frequency $(2 \pi f)$ and $f$ symbolizes frequency.

5.3. Surface Dielectric Probe Laboratory Equipment. The surface dielectric probe and electrical conductivity laboratory equipment used in this study was the Adek Percometer, which measured the dielectric values of specimens in the laboratory. The Adek Percometer used in this study was a $50 \mathrm{MHz}$ dielectric probe and is pictured in Figure 5.

Samples of the three soils were prepared at standard Proctor optimum dry density in $100 \mathrm{~mm}$ by $200 \mathrm{~mm}$ polyvinylchloride cylindrical containers. The Adek Percometer laboratory device employs a sealed surface probe and measures the material permittivity as a function of the change in capacitance of the probe due to the permittivity of the material, as seen in the following equation [15]

$$
\Delta C=C_{a}\left(\varepsilon_{r}-1\right)
$$

where $\Delta C$ is change in capacity measured by probe, $C_{a}$ represents active capacitance of the probe and $\varepsilon_{r}$ denotes relative permittivity of material.

\section{Experimental Results}

This section summarizes the results of the GPR, the complex dielectric network analyzer, and the surface dielectric probe. Permittivity results and a comparison of the dielectric constants measured with each device are provided in Table 3.

6.1. GPR Results. As seen in Figure 3, the dielectric constants of the three soils were evaluated with a one $\mathrm{GHz}$ central frequency pulse radar air-coupled antenna. Each box sample was compacted to the specified optimum standard Proctor dry density at three moisture contents. Continuous temperature monitoring of the environmental rooms showed an overall variation in temperature of approximately $\pm 0.5^{\circ} \mathrm{C}$ during the climatic conditioning. 


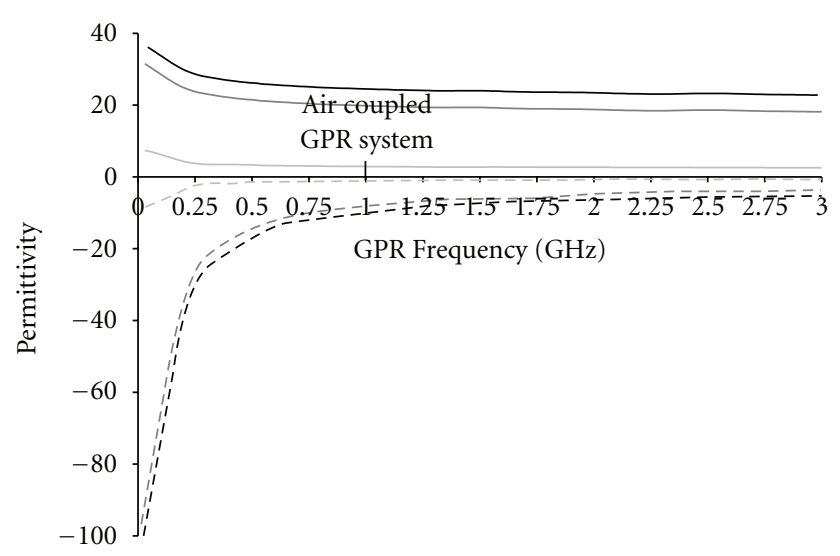

(a) $+20^{\circ} \mathrm{C}$

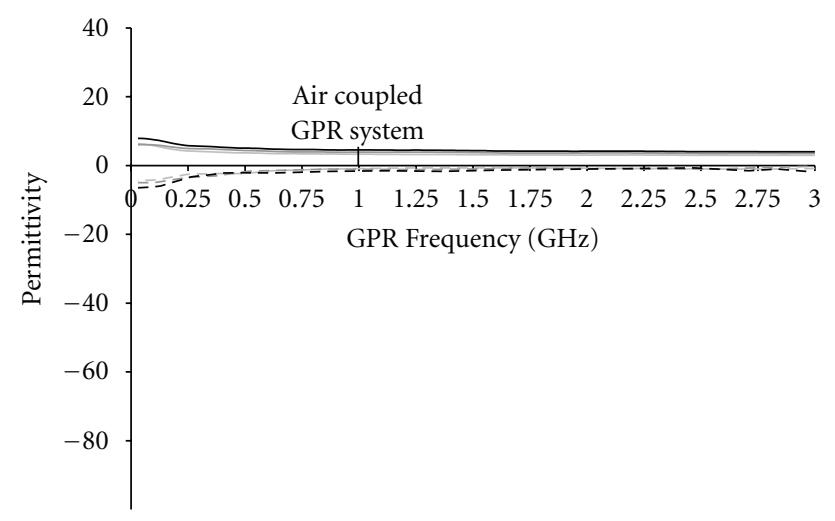

- Real dielectric at $12 \%$ moisture

- Real dielectric at $16 \%$ moisture

_ Real dielectric at $21 \%$ moisture

- - - Imaginary dielectric at $12 \%$ moisture

- - - Imaginary dielectric at $16 \%$ moisture

- - - Imaginary dielectric at 21\% moisture

$$
\text { (b) }-20^{\circ} \mathrm{C}
$$

Figure 7: Complex dielectric network analyzer results of intermediate plastic clay-till.

The results of the GPR permittivity measurements across the three soils evaluated are summarized in Table 3. As seen in Table 3, the dielectric constant measurements obtained from the field GPR were significantly reduced when measured at minus 20 degrees celsius, compared to measurements taken at plus 20 degrees celsius. Additionally, at plus 20 degrees celsius, the dielectric constant of each soil type was observed to decrease with a reduction of moisture content. Since the field GPR-measured dielectric constant is primarily influenced by water, this was expected.

At plus 20 degrees celsius, field GPR dielectric constant measurements were found to be similar to the values listed in Table 1. For example, the gravel base field GPR-measured dielectric constant ranged from 4.6 to 10.8, and the published dielectric values for glacial-alluvium gravel base listed in Table 1 ranged from 4 to 7 . Similarly, the clay-till subgrade

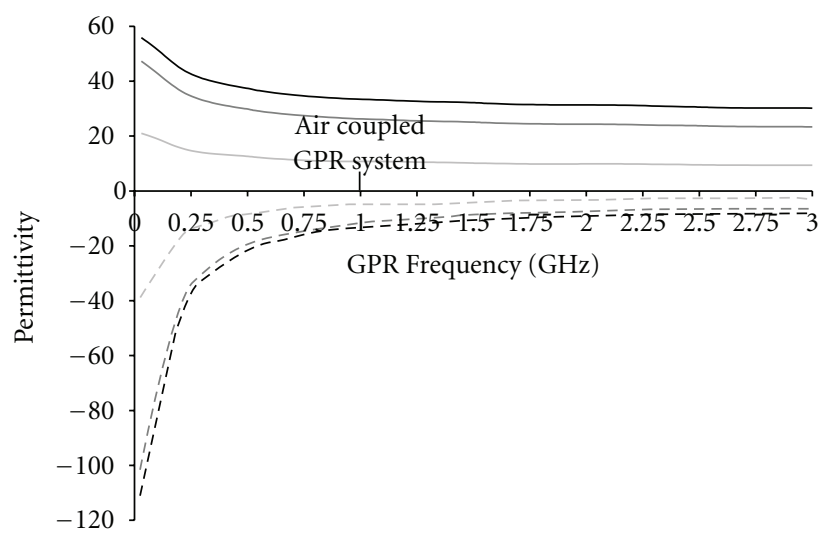

(a) $+20^{\circ} \mathrm{C}$

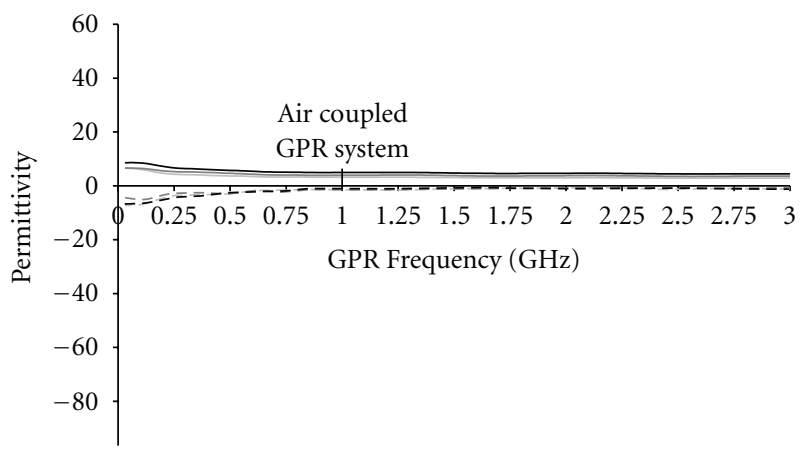

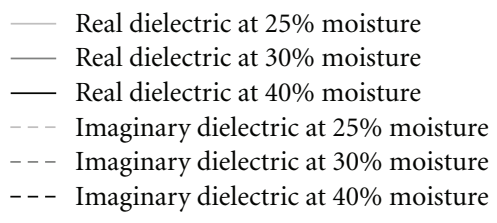

(b) $-20^{\circ} \mathrm{C}$

Figure 8: Complex dielectric network analyzer results of high plastic lacustrine clay.

GPR-measured dielectric constant varied from 8.5 to 19.8 , and the published dielectric constant for glacial till ranged from 8 to 18 in Table 1. The high plastic lacustrine clay subgrade field GPR dielectric constant measurements ranged from 7.6 to 38.6, which also concurred with the published dielectric constant measurements ranging from 25 to 40 summarized in Table 1 [11].

At a temperature of minus 20 degrees celsius, soil types could still be differentiated by GPR-measured dielectric constant; however, the specific soil types could not be specifically identified due to reduction in sensitivity of dielectric permittivity at frozen condition state of the soil.

As also seen in Table 3, the field GPR-measured permittivity of the clay-till and the lacustrine clay soils were significantly higher than those obtained for the granular base across moisture contents at or above each soil's respective 


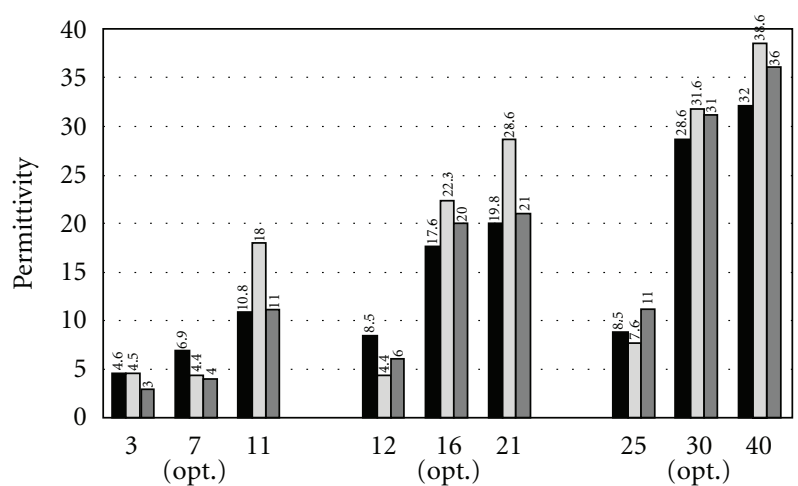

Glacial-alluvium Intermediate plastic High plastic gravel base clay-till lacustrine clay

- Air coupled GPR system (1 GHz)

$\square$ Network analyzer $(1 \mathrm{GHz})$

$\square$ Adek surface analyzer $(50 \mathrm{MHz})$

(a) $+20^{\circ} \mathrm{C}$

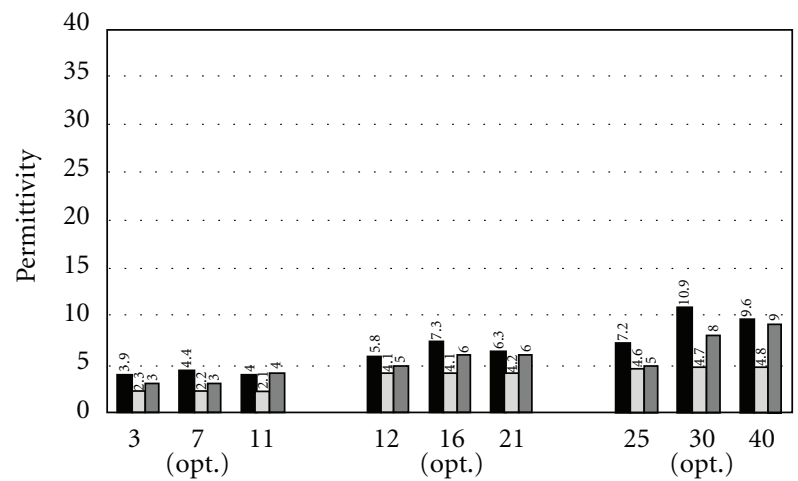

Glacial-alluvium Intermediate plastic High plastic gravel base clay-till lacustrine clay

- Air coupled GPR system (1 GHz)

$\square$ Network analyzer $(1 \mathrm{GHz})$

$\square$ Adek surface analyzer $(50 \mathrm{MHz})$

(b) $-20^{\circ} \mathrm{C}$

FIGURE 9: Summary of permittivity results.

optimum moisture content. The increase in permittivity as a function of increasing moisture content is assumed to be primarily attributed to the higher volumetric moisture content inherent in fine-grained soils. As a result, the significantly lower dielectric measurements obtained for the coarse-grained soil (gravel base), relative to those of the fine-grained soils (clay-till and lacustrine clay), may make it possible to use the field GPR system to distinguish between coarse-grained and fine-grained soils at or above optimum moisture content when the soils are thawed.

\subsection{Complex Dielectric Network Laboratory Analyzer Results.} The real and imaginary components of the complex soil permittivity measurements obtained from the complex dielectric network laboratory analyzer at plus 20 degrees celsius and minus 20 degrees celsius across frequencies ranging from $0.03 \mathrm{GHz}$ to $3.0 \mathrm{GHz}$ are illustrated in Figure 6 through Figure 8. To compare with the field GPR results, $1.0 \mathrm{GHz}$ is marked in the plots in Figure 6 to Figure 8. As seen in Figure 6 to Figure 8, both the real and imaginary components of the radar signal for the three soils exhibited a significant range in permittivity across temperature and moisture content, particularly at lower frequencies. As seen in Figures 7 and 8, variation in the imaginary component of the permittivity was particularly more pronounced than the real component at frequencies less than $0.25 \mathrm{GHz}$. This was observed in unfrozen samples of the fine-grained soils, clay-till and lacustrine clay, at moisture contents at or above standard Proctor optimum moisture.

Based on the data compiled, there are potential advantages to characterizing the real and imaginary components of the permittivity signal. The imaginary component of the permittivity signal is believed to be primarily a function of the dispersion of the radar energy due to water content within the material. A higher imaginary component of the material permittivity means a larger attenuation of the signal within the material. The imaginary component of the signal may be used to help estimate moisture content of the material. As such, the imaginary component of the permittivity signal at frequencies of less than $0.25 \mathrm{GHz}$ may be used to more accurately determine the moisture content of unfrozen fine-grained soils. Based on the results of this study, the use of low-frequency complex permittivity should be considered for quantifying soil moisture contents.

As seen in Table 3, at plus 20 degrees celsius, the dielectric constant of the fine-grained soils was significantly greater than those of the coarse-grained soil across all moisture contents. However, at minus 20 degrees celsius, the permittivity measurements of the fine-grained soils are only slightly greater than those of the granular gravel base across all moisture contents. Overall, at plus 20 degrees celsius, the network analyzer dielectric constant measurements for each soil type concurred to the published values listed in Table 1, just as the field GPR measurement system did.

6.3. Surface Dielectric Probe Results. The results of the Adek Percometer dielectric constant measurements are summarized in Table 3. As seen in Table 3, the Adek Percometer permittivity measurements obtained from granular base at plus 20 degrees celsius ranged from 3.0 to 11.0. However, the gravel base at minus 20 degrees celsius showed a significant reduction in permittivity as well as lower values, ranging from 3.0 to 4.0 .

As seen in Table 3, the dielectric constant measurements obtained from the Adek Percometer were reduced significantly when measured at minus 20 degrees celsius as opposed to plus 20 degrees celsius. At plus 20 degrees celsius, the dielectric constants of each soil type were reduced with a reduction of moisture content. At a temperature of plus 20 degrees celsius, Adek Percometer dielectric constant measurements concurred with the values listed in Table 1 . For example, at 20 degrees celsius, the gravel base Adek Percometer-measured dielectric constant ranged from 3.0 to 11.0 , and the dielectric values for glacial-alluvium gravel base are listed in Table 1 range from 4 to 7. Similarly, 
the clay-till subgrade Adek Percometer-measured dielectric constant varied from 6.0 to 21.0 at 20 degrees celsius and is listed to range from 11 to 36 [11]. At a temperature of minus 20 degrees celsius, the difference between a granular soil and a fine-grained soil may be identified; however, there was not a significant difference between the Adek Percometer dielectric constant measurements of the two fine-grained soils, clay-till subgrade, and high plastic lacustrine clay.

As also seen in Table 3, the Adek Percometer-measured permittivity of the clay-till and that of the lacustrine clay soils were significantly higher than those obtained for the granular base across moisture contents at or above each soil's respective optimum moisture content. The increase in permittivity observed in the clay soils as a function of increasing moisture content is assumed to be primarily attributed to the naturally occurring higher volumetric moisture content of fine-grained soils. As a result, the significantly lower dielectric measurements obtained for the coarse granular soil (gravel base), relative to those of the fine-grained soils (clay-till and lacustrine clay), may make it possible to use the laboratory Adek Percometer to distinguish between coarse-grained and fine-grained soils at or above optimum moisture content when the soils are unfrozen.

\section{Summary of Results}

Table 3 summarizes and Figure 9 illustrates the dielectric constant measurements obtained from the air-coupled GPR system, the complex network analyzer, and the Adek Percometer surface dielectric probe employed in this study. The differences between the dielectric constant measurements of two laboratory devices, the complex dielectric network analyzer and the Adek Percometer surface dielectric probe, and the field GPR system are listed in Table 3. Across all soil types, moisture contents, and both fields state temperatures, the dielectric constants measured with the Adek Percometer differed from -2.9 to +2.4 when compared to the field GPR system. In contrast, the dielectric constant measured with the complex dielectric network analyzer differed from -6.2 to +8.8 when compared to the field GPR system.

Figure 9 illustrates a comparison of the two laboratory devices and the field GPR system permittivity results across soil types, moisture contents, and temperatures considered in this study. This graphical representation shows the significant reduction in dielectric constant when measured at minus 20 degrees celsius. Therefore, measurement of water content is best suited at temperatures greater than 20 degrees celsius. Figure 9 also shows that the Adek Percometer laboratory device-measured dielectric constants were closer to those measured using the GPR equipment.

\section{Conclusion}

This study was undertaken to determine if the permittivity measured using field GPR was sufficiently sensitive to characterize differences in soil type, moisture content, and presence of frost within typical soils used to construct roads in Saskatchewan. As well, this study was set out to compare the dielectric constant measurements of two laboratory test devices to those obtained using the GPR system. Three road soil types that represent the typical spectrum of soils that are used to construct Saskatchewan roads were considered in this study: crushed glacial-alluvium gravel base, intermediate plastic clay-till, and high plastic lacustrine clay. Each soil type was characterized across typical moisture states experienced in Saskatchewan field state conditions.

The complex dielectric network analyzer, the Adek Percometer, and the field GPR system used in this study measured the dielectric constant of the soils accurately at temperatures greater than zero degrees celsius. The highest sensitivity in permittivity of soils was observed at temperatures greater than zero degrees celsius. All three systems measured dielectric constants that differentiated between coarse-grained and fine grained soils when used at temperatures above-freezing. In addition, at these above freezing temperatures, all three permittivity measurement systems identified the presence of varied water content in soils considered.

The Adek Percometer is recommended to determine the water content of laboratory-prepared soil samples. GPR technology can be used to characterize the substructure soil type and moisture content of road substructure soils. Given the influence of road soil type and moisture content on inservice road performance, this ability could provide road engineers with the ability to accurately assess the in situ structural condition of road structures for preservation and rehabilitation planning purposes. In addition, the ability to accurately estimate road substructure moisture condition spatially using nontraffic intrusive and nondestructive survey technology could provide road agencies with the ability to accurately assess road structural performance.

\section{Acknowledgments}

The authors would like to thank Saskatchewan Ministry of Highways and Infrastructure and the City of Saskatoon for their sponsorship of this paper. The authors would also like to acknowledge the Texas Transportation Institute and Roadscanners Oy for their assistance and use of lab facilities for conducting the tests for this research.

\section{References}

[1] C. Berthelot, B. Marjerison, G. Houston, J. McCaig, S. Warrener, and R. Gorlick, "Mechanistic comparison of cementand bituminous-stabilized granular base systems," Transportation Research Record, no. 2026, pp. 70-80, 2007.

[2] C. Berthelot, "Structural evaluation of frost penetration of thin membrane surfaced roads," Prepared for the Saskatchewan Department of Highways and Transportation, Saskatoon, Canada, 2007.

[3] G. Sparks and E. Sauer, Analysis of Spring Road Restrictions on Yukon Highways. Volumes 1 and 2, University of Saskatchewan, Saskatoon, Canada, 1991.

[4] C. Berthelot, T. Scullion, R. Haichert, and B. Marjerison, "Use of ground penetrating radar to diagnose highway structural composition and moisture problems," in Proceedings of the 84th Annual Meeting of the Transportation Research Board, 
Washington, DC, USA, 2005, CDROM Proceedings-Paper \#05-1213.

[5] K. Grote, S. Hubbard, and Y. Rubin, "GPR monitoring of volumetric water content in soils applied to highway construction and maintenance," Leading Edge, vol. 21, no. 5, pp. 482-485, 2002.

[6] K. Grote, S. Hubbard, J. Harvey, and Y. Rubin, "Evaluation of infiltration in layered pavements using surface GPR reflection techniques," Journal of Applied Geophysics, vol. 57, no. 2, pp. 129-153, 2005.

[7] A. Benedetto and S. Pensa, "Indirect diagnosis of pavement structural damages using surface GPR reflection techniques," Journal of Applied Geophysics, vol. 62, no. 2, pp. 107-123, 2007.

[8] T. Scullion, C. Yiqing, and L. Lau, "Colormap-user's manual with case studies," Tech. Rep. 1341-1, Texas Transportation Institute, College Station, Tex, USA, 1993.

[9] T. Saarenketo and T. Scullion, "Ground penetrating radar applications on roads and highways," Tech. Rep. 1923-2F, Texas Transportation Institute, College Station, Tex, USA, 1994.

[10] M. Knoll and R. Knight, "Relationships between dielectric and hydrogeologic properties of sand-clay mixtures," in Proceedings of the 5th International Conference on Ground Penetrating Radar, pp. 45-61, Englewood, Colo, USA, 1994.

[11] T. Saarenketo, Electrical properties of road materials and subgrade soils and the use of ground penetrating radar in traffic infrastructure surveys, Ph.D. thesis, University of Oulu, Oulu, Finland, 2006.

[12] T. Saarenketo, "Using ground-penetrating radar and dielectric probe measurements in pavement density quality control," Transportation Research Record, no. 1575, pp. 34-41, 1997.

[13] T. Saarenketo and T. Scullion, "Using electrical properties to classify the strength properties of base course aggregates," Tech. Rep. 1341-2, Texas Transportation Institute, College Station, Tex, USA, 1995.

[14] T. Scullion, L. Lau, and Y. Chen, "Implementation of the Texas ground penetrating radar system," Tech. Rep. 1233-1, Texas Transportation Institute, College Station, Tex, USA, 1992.

[15] T. Plakk, "HF permittivity measurements by capacity probe: user's manual," Adek Ltd., Estonia, 1994. 

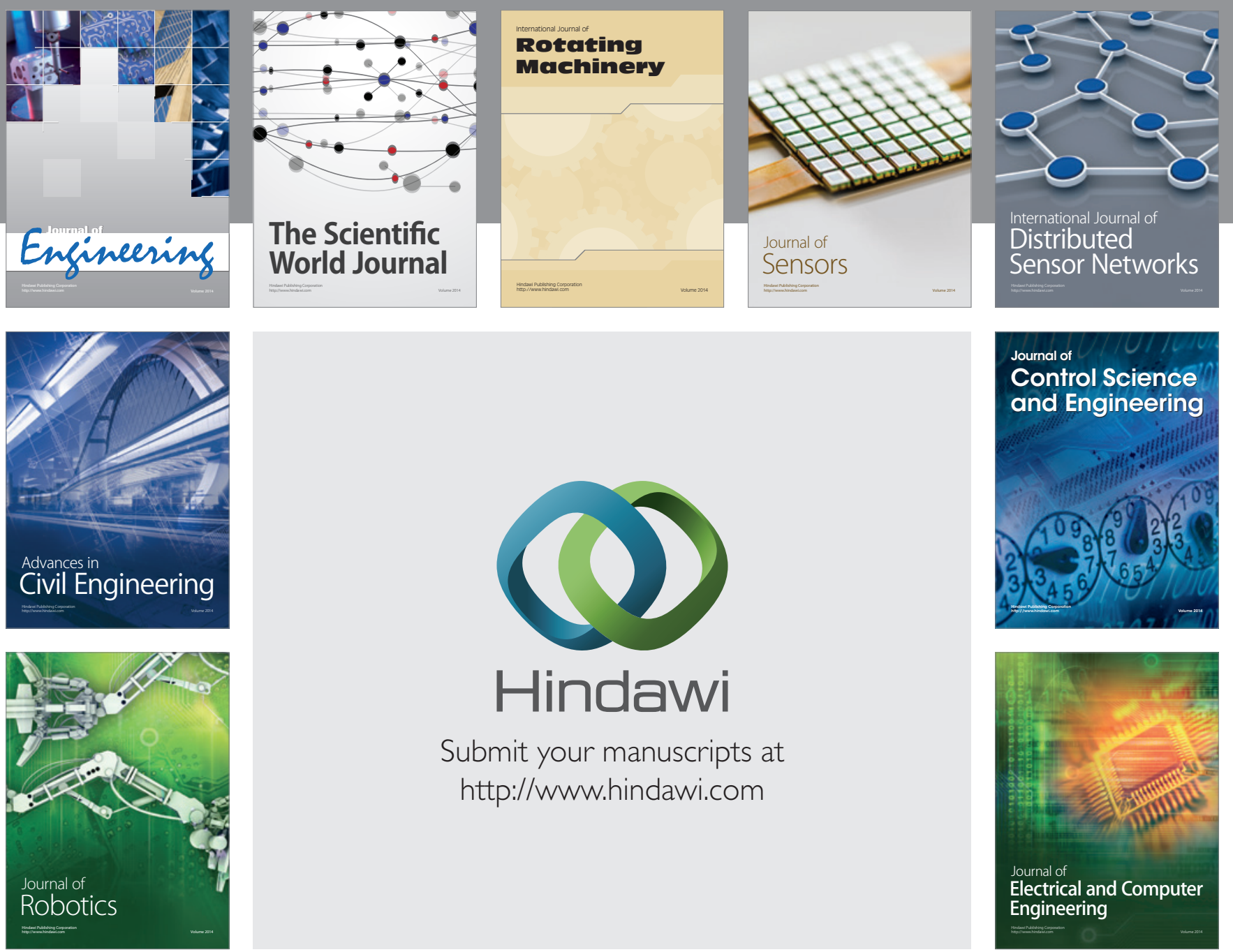

Submit your manuscripts at

http://www.hindawi.com
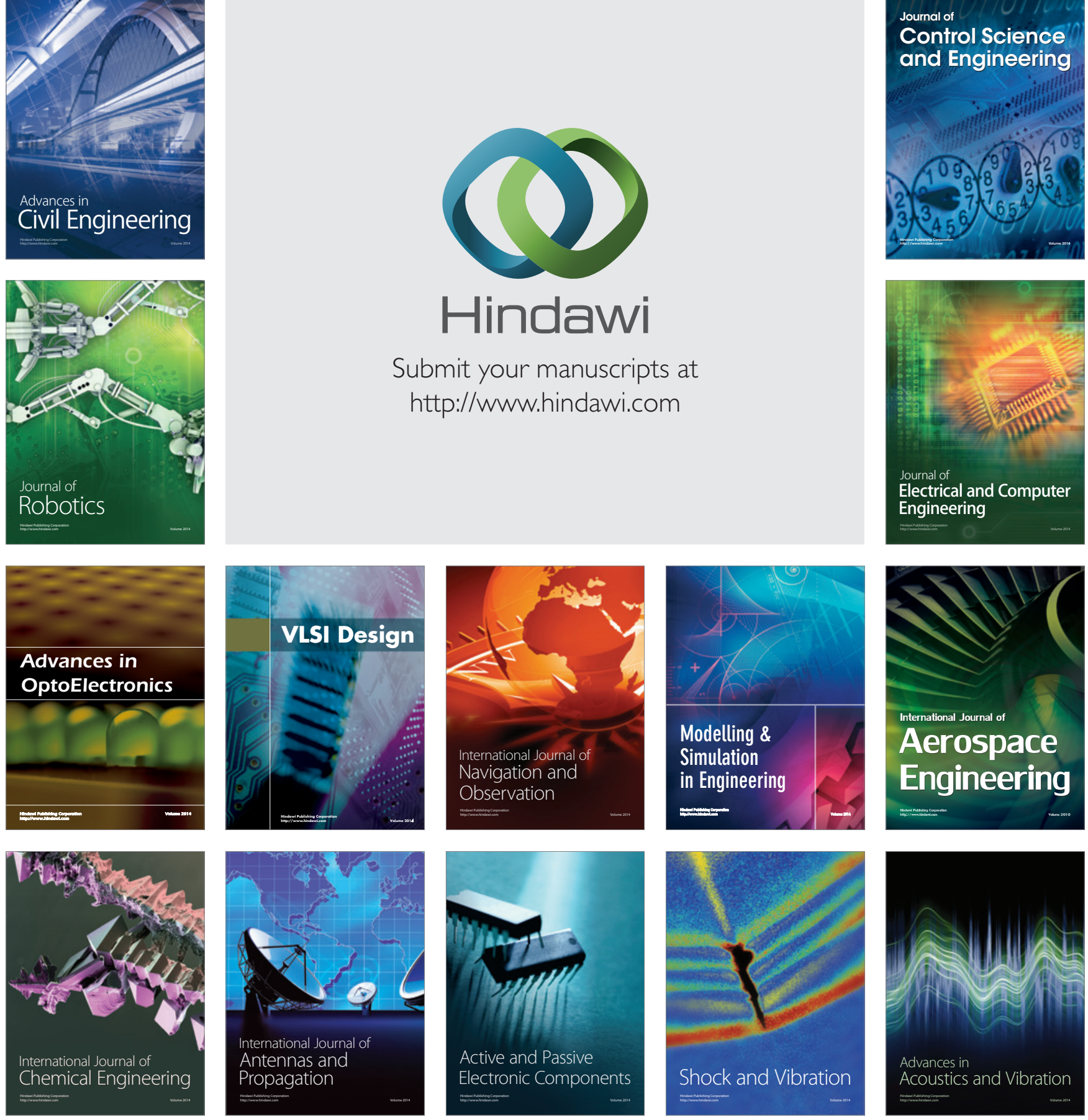